\title{
Photocatalytic Activity and Optical Properties of Blue Persistent Phosphors under UV and Solar Irradiation
}

\author{
C. R. García, ${ }^{1,2}$ L. A. Diaz-Torres, ${ }^{1}$ J. Oliva, ${ }^{1}$ M. T. Romero, ${ }^{2}$ and P. Salas ${ }^{3}$ \\ ${ }^{1}$ Laboratorio de Fotocatálisis y Fotosíntesis Artificial, Centro de Investigaciones en Óptica, AP 1-948, 37150 León, GTO, Mexico \\ ${ }^{2}$ Facultad de Ciencias Físico Matemáticas, Universidad Autónoma de Coahuila, Camporredondo, 25000 Saltillo, COAH, Mexico \\ ${ }^{3}$ Centro de Física Aplicada y Tecnología Avanzada, Universidad Nacional Autónoma de México, AP 1-1010, \\ 76000 Juriquilla, QRO, Mexico
}

Correspondence should be addressed to L. A. Diaz-Torres; ditlacio@cio.mx

Received 25 February 2016; Revised 12 June 2016; Accepted 25 July 2016

Academic Editor: Meenakshisundaram Swaminathan

Copyright (C) 2016 C. R. García et al. This is an open access article distributed under the Creative Commons Attribution License, which permits unrestricted use, distribution, and reproduction in any medium, provided the original work is properly cited.

Blue phosphorescent strontium aluminosilicate powders were prepared by combustion synthesis route and a postannealing treatments at different temperatures. X-ray diffraction analysis showed that phosphors are composed of two main hexagonal phases: $\mathrm{SrAl}_{2} \mathrm{O}_{4}$ and $\mathrm{Sr}_{3} \mathrm{Al}_{32} \mathrm{O}_{51}$. The morphology of the phosphors changed from micrograins $\left(1000^{\circ} \mathrm{C}\right)$ to a mixture of bars and hexagons $\left(1200^{\circ} \mathrm{C}\right)$ and finally to only hexagons $\left(1300^{\circ} \mathrm{C}\right)$ as the annealing temperature is increased. Photoluminescence spectra showed a strong blue-green phosphorescent emission centered at $\lambda_{\mathrm{em}}=455 \mathrm{~nm}$, which is associated with $4 \mathrm{f}^{6} 5 \mathrm{~d}^{1} \rightarrow 4 \mathrm{f}^{6}\left({ }^{8} \mathrm{~S}_{7 / 2}\right)$ transition of the $\mathrm{Eu}^{2+}$. The sample annealed at $1200^{\circ} \mathrm{C}$ presents the highest luminance value $\left(40 \mathrm{Cd} / \mathrm{m}^{2}\right)$ with $\mathrm{CIE}$ coordinates $(0.1589,0.1972)$. Also, the photocatalytic degradation of methylene blue (MB) under UV light (at $365 \mathrm{~nm}$ ) was monitored. Samples annealed at $1000^{\circ} \mathrm{C}$ and $1300^{\circ} \mathrm{C}$ presented the highest percentage of degradation (32\% and 38.5\%, resp.) after 360 min. In the case of photocatalytic activity under solar irradiation, the samples annealed at $1000^{\circ} \mathrm{C}, 1150^{\circ} \mathrm{C}$, and $1200^{\circ} \mathrm{C}$ produced total degradation of $\mathrm{MB}$ after only $300 \mathrm{~min}$. Hence, the results obtained with solar photocatalysis suggest that our powders could be useful for water cleaning in water treatment plants.

\section{Introduction}

Long persistent phosphor (LPP) materials have several applications such as emergency signals in the darkness, wall painting, radiation detection, displays, lamps, and decorations [1]. Due to their importance, the development of new LPP with stable chemical and physical properties is still a challenge in the field of materials science. Long persistent $\mathrm{SrAl}_{2} \mathrm{O}_{4}: \mathrm{Eu}^{2+}{ }^{2+} \mathrm{Dy}^{3+}(510 \mathrm{~nm})$ phosphors have shown high brightness lasting for $10 \mathrm{~h}[2,3]$. Similarly, blue phosphorescent emission at around $\lambda_{\mathrm{em}}=450 \mathrm{~nm}$ has been obtained from $\mathrm{CaAl}_{2} \mathrm{O}_{4}: \mathrm{Eu}^{2+}, \mathrm{Nd}^{3+}(430 \mathrm{~nm})$, $\mathrm{SrMgSi}_{2} \mathrm{O}_{6}: \mathrm{Dy}^{3+}(455 \mathrm{~nm})$, and $\mathrm{BaMgAl}_{10} \mathrm{O}_{17}: \mathrm{Eu}^{2+}, \mathrm{Co}^{3+}$ $(450 \mathrm{~nm})$ systems $[1,4]$. Nonetheless, these systems showed less brightness and time of phosphorescence than those for the green $\mathrm{SrAl}_{2} \mathrm{O}_{4}: \mathrm{Eu}^{2+}, \mathrm{Dy}^{3+}$ phosphor. Thus, the development of new blue LPPs materials with blue emission at around $450 \mathrm{~nm}$ is required for the applications mentioned above.
Besides, few reports have demonstrated the use of the LPPs in the photocatalysis area. It has been proposed that the mixture of LPPs and photocatalyst composites can help to improve the photocatalytic process under ultraviolet (UV) light excitation: The photocatalyst/LPP composites such as $\mathrm{TiO}_{2} / \mathrm{SrAl}_{2} \mathrm{O}_{4}: \mathrm{Eu}^{2+}, \mathrm{Dy}^{3+}$ have been proposed to enhance the benzene oxidation under UV light or in the darkness [5]. Another composite, $\mathrm{Ti}_{2-x} \mathrm{~N}_{y} \mathrm{O}_{2} / \mathrm{CaAl}_{2} \mathrm{O}_{4}: \mathrm{Eu}^{2+}, \mathrm{Dy}^{3+}$, was used to decompose gaseous acetaldehyde or nitrogen oxide acetaldehyde by a self-fluorescence assisted in the dark [6]. Another composite, $\mathrm{Ag}_{3} \mathrm{PO}_{4} / \mathrm{Sr}_{4} \mathrm{Al}_{14} \mathrm{O}_{25}$ :(Eu,Dy), decomposed the Rhodamine $\mathrm{B}$ without light assistance [7]. Here, the photocatalyst $\mathrm{Ag}_{3} \mathrm{PO}_{4}$ is excited by the light emitted from the LPP after turning off the UV excitation which was maintained during 30 minutes, this produced the degradation of rhodamine dissolved in an aqueous solution [7], then, and few studies about the photocatalytic properties of LPPs have been published. 
The utilization of LPPs for photocatalytic applications has been attractive because the phosphorescent materials have electrons with high mobility from the valence band (VB) levels to the traps levels which can act as electrons storage and this fact can favor the photocatalytic properties [8]. These traps levels are usually generated by oxygen vacancy, defects, or impurities when the lattice is doped with $\mathrm{Eu}^{2+}$ and $\mathrm{Dy}^{3+}$ ions [8]. Based on the phosphorescence models, it is argued that electrons are stored in these traps states and, then, the energy can be slowly released to produce phosphorescence by electrons and holes recombination [9]. This slow release of electrons can allow larger amounts of electrons and holes $\left(\mathrm{e}-\mathrm{h}^{+}\right)$to be available for the production of hydroxyl radicals $\left(\mathrm{OH}^{-}\right)$which promotes the photocatalysis process [10]. The study of the photocatalytic properties of LPPs is important to find alternative photocatalysts other than $\mathrm{TiO}_{2}$ which has been recently pointed out as a toxic for aquatic ecosystems [11]. Furthermore, several studies show that nanosized $\mathrm{TiO}_{2}$ is toxic for many aquatic species like fish Daphnia magna and Rainbow fish [12]. Bioaccumulation into the gills of river fishes has also been reported [13]. Hence, micrometric sizes of the grains of the photocatalyst are suitable because they can be easily removed from water after their use. In addition, there are very few studies about $\mathrm{Eu}^{2+}, \mathrm{Dy}^{3+}$ doped strontium/aluminosilicate powders and their utilization as photocatalysts. Thus, the aim of this work is to investigate the photocatalytic, structural, morphological, and optical properties of $\mathrm{Eu}^{2+}, \mathrm{Dy}^{3+}$ doped-aluminate/aluminosilicate phosphors annealed at different temperatures in the range of $1000^{\circ} \mathrm{C}-1300^{\circ} \mathrm{C}$.

\section{Experimental}

2.1. Combustion Synthesis. $\mathrm{Na}_{2} \mathrm{O}_{3} \mathrm{Si} 5 \mathrm{H}_{2} \mathrm{O}$ (99.99\%), $\mathrm{Sr}\left(\mathrm{NO}_{3}\right)_{3} \cdot \mathrm{H}_{2} \mathrm{O} \quad(99.9965 \%), \quad \mathrm{Al}\left(\mathrm{NO}_{3}\right)_{3} \cdot 9 \mathrm{H}_{2} \mathrm{O} \quad(99.5 \%)$, $\mathrm{DyCl}_{3} \cdot 6 \mathrm{H}_{2} \mathrm{O}$ (99.9\%), $\quad \mathrm{EuCl}_{3} \cdot 6 \mathrm{H}_{2} \mathrm{O}$ (99.9\%), $\quad \mathrm{NH}_{4} \mathrm{NO}_{3}$ (99.9\%), and $\mathrm{H}_{3} \mathrm{BO}_{3}$ (95\%) reagents from Sigma Aldrich were dissolved in $25 \mathrm{~mL}$ of deionized water for approximately 45 minutes in a quartz beaker on a magnetic stirrer, and a transparent solution was formed. The $\mathrm{Al} / \mathrm{Sr}$ ratio was 7.6 for all samples and was prepared using 0.01 moles of $\mathrm{Eu}^{2+}, 0.02$ mole of $\mathrm{Dy}^{3+}, 1.5 \times 10^{-3}$ mole of $\mathrm{NH}_{4} \mathrm{NO}_{3}$, and $6.0 \times 10^{-4}$ mole of $\mathrm{H}_{3} \mathrm{BO}_{3}$. Also 0.01 mole of urea $\left[\mathrm{CH}_{4} \mathrm{~N}_{2} \mathrm{O}\right]$ was added as fuel and it maximizes the combustion reaction. Next, the transparent blend was annealed at $600^{\circ} \mathrm{C}$ in atmospheric pressure and the exothermic reaction occurred (combustion process) during 10-40 seconds. As a result, (Eu,Dy)doped strontium aluminate/aluminosilicates as-synthesized powders were obtained. Finally, the as-synthesized powders were put in alumina crucibles and annealed under reductive atmosphere during $4 \mathrm{~h}$ at four different temperatures: $1000^{\circ} \mathrm{C}$, $1150^{\circ} \mathrm{C}, 1200^{\circ} \mathrm{C}$, and $1300^{\circ} \mathrm{C}$. After this, the blue-emitting LPPs of (Eu,Dy)-doped strontium aluminate/aluminosilicate powders were obtained.

2.2. Photocatalysis under UV and Solar Irradiations. For the photocatalysis experiments, the powders were first ground in an agate mortar until we got fine powders. The photocatalytic degradation of the methylene blue (MB) was measured by monitoring the absorbance of $\mathrm{MB}$ dissolved in water at $665 \mathrm{~nm}$. The photocatalytic process was carried out using a reactor fabricated with three $4 \mathrm{~W}$ UV lamps. Those lamps emitted UV light centered at $365 \mathrm{~nm}$, with a FWHM around $12 \mathrm{~nm}$. The samples for photocatalysis were prepared by mixing $30 \mathrm{mg}$ of (Eu,Dy)-doped strontium aluminate/aluminosilicate powders with a solution $0.5 \mathrm{mM}$ of $\mathrm{MB}$ in water. This solution was stirred in darkness during $1 \mathrm{~h}$ in order to adsorb the MB molecules on the surface of the powders. Afterwards, the UV lamps were turned on and samples of $1 \mathrm{~mL}$ were extracted every 30 minutes, the powders were separated from the liquid using centrifugation, and, then, the absorbance spectrum of the liquid was obtained by using a Cary-60 UV-Vis spectrophotometer in the range of $200 \mathrm{~nm}-700 \mathrm{~nm}$. In the case of solar photocatalysis, the samples were exposed under sunlight during a sunny day from 10:00 am to 4:00 pm in Saltillo city, Mexico. The coordinates in this location were as follows: latitude, $25^{\circ} 25.706^{\prime}$ North, longitude, $100^{\circ} 58.616^{\prime}$ West, and height, $1581 \mathrm{~m}$. The average solar irradiance was $\delta=678 \pm 43 \mathrm{~W} / \mathrm{m}^{2}$ and it was measured with a photodiode 6450 Davis Solar Radiation Sensor.

2.3. Structural and Morphological Characterization. The Xray diffraction (XRD) patterns of the (Eu,Dy)-doped strontium aluminate/aluminosilicate $\left(1000-1300^{\circ} \mathrm{C}\right)$ were performed in a Bruker D-8 Advance diffractometer having the Bragg-Brentano configuration and $\mathrm{CuK}_{\alpha}$ radiation $(\lambda=$ $1.5406 \AA$ ). The XRD patterns were measured in the range of $5^{\circ} \leq 2 \theta \leq 80^{\circ}$ with $0.02^{\circ}$ step size. Morphology of the samples was analyzed using a field emission electron JSM$7800 \mathrm{~F}$ microscope and $200 \mathrm{kV}$ of accelerating voltage.

2.4. Optical Characterization. Excitation spectra, photoluminescence spectra, and phosphorescence decay curves were obtained by using an Acton Research modular 2300 fluorometer. The fluorometer was coupled with a pair of SP500i monochromators (Acton Research), a Xenon lamp (75 W) as excitation source of $75 \mathrm{~W}$ Xenon lamp, and a photo multiplier tube R955 (Hamamatsu). The chromaticity coordinates and the luminance of the samples were taken by using a Konica Minolta CS-2000 luminometer. For the measurements of phosphorescence, the (Eu,Dy)-doped strontium aluminate/aluminosilicate powders were irradiated during 5 minutes with a $365 \mathrm{~nm}$ UV lamp; then, the excitation was stopped and the phosphorescent signal as well as the luminance $\left(L_{v}\right)$ was measured. The reflectance spectra of the powder samples were measured by utilizing Cary-5000 spectrophotometer coupled integrating sphere in the range of $200 \mathrm{~nm}-700 \mathrm{~nm}$. All optical measurements were made at room temperature.

\section{Results and Discussion}

3.1. Structure and Morphology. Figure 1 show the XRD patterns of the (Eu,Dy)-doped strontium aluminate/aluminosilicate powders annealed in the range of $1000^{\circ} \mathrm{C}-1300^{\circ} \mathrm{C}$. The samples annealed at $1150^{\circ} \mathrm{C}, 1200^{\circ} \mathrm{C}$, and $1300^{\circ} \mathrm{C}$ presented 
TABLE 1: Summary of the luminance values, energy band- gap estimated values, CIE coordinate, and morphology of the samples annealed at different temperatures.

\begin{tabular}{lcccc}
\hline Sample & $L_{v}\left(\mathrm{Cd} / \mathrm{m}^{2}\right)$ & Energy gap $(\mathrm{eV})$ & CIE coordinates $(x, y)$ & Morphology \\
\hline $1000^{\circ} \mathrm{C}$ & 6 & 5.5 & $(0.2934,0.3355)$ & Irregular micrograins \\
$1150^{\circ} \mathrm{C}$ & 27 & 5.8 & $(0.1708,0.2209)$ & Bars, grains, and hexagons \\
$1200^{\circ} \mathrm{C}$ & 40 & 5.7 & $(0.1589,0.1972)$ & Bars and hexagons \\
$1300^{\circ} \mathrm{C}$ & 15 & 5.8 & $(0.1637,0.2048)$ & Hexagons \\
\hline
\end{tabular}

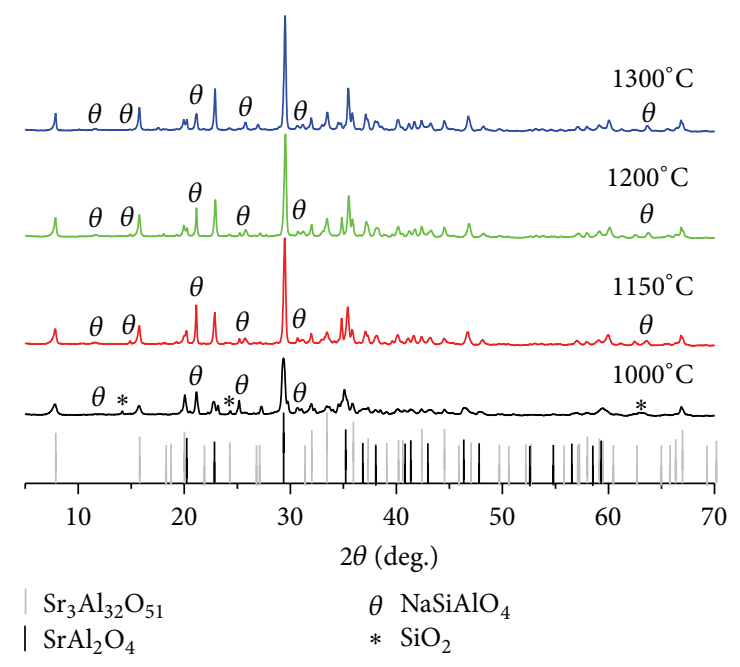

FIGURE 1: XRD patterns of the samples as function of temperature.

three crystalline phases: firstly, the $\mathrm{SrAl}_{2} \mathrm{O}_{4}$ hexagonal phase (JCPDS 311336), second the $\mathrm{Sr}_{3} \mathrm{Al}_{32} \mathrm{O}_{51}$ hexagonal phase (JCPDS 440024), and lastly the $\mathrm{NaSiAlO}_{4}$ orthorhombic phase (JCPDS 390376). The sample annealed at $1000^{\circ} \mathrm{C}$ had a fourth phase $\mathrm{SiO}_{2}$, and it is labeled with the symbol *. The $\mathrm{SrAl}_{2} \mathrm{O}_{4}$ and $\mathrm{Sr}_{3} \mathrm{Al}_{32} \mathrm{O}_{51}$ standard patterns are plotted at the bottom of Figure 1 in black and gray vertical lines and the $\mathrm{NaSiAlO}_{4}$ phase is marked with the $\theta$ symbol on the XRD patterns in all the samples. Furthermore, the intensity of the diffraction peaks of the $\mathrm{NaSiAlO}_{4}$ phase is higher for the samples annealed at $1150^{\circ} \mathrm{C}$ and $1200^{\circ} \mathrm{C}$ in comparison with the samples annealed at $1000^{\circ} \mathrm{C}$ and $1300^{\circ} \mathrm{C}$. This suggests that the amount of the $\mathrm{NaSiAlO}_{4}$ is lower in the samples annealed at $1150^{\circ} \mathrm{C}$ and $1200^{\circ} \mathrm{C}$.

The morphology of the calcined samples is illustrated in Figures $2(\mathrm{a})-2(\mathrm{~d})$. The sample annealed at $1000^{\circ} \mathrm{C}$ shows clusters of coalesced grains in the range of $1-5 \mu \mathrm{m}$. Also, it can be observed that these irregular grains are porous, which can be beneficial for the adsorption of MB molecules on the surface of the powders. The samples annealed at $1150^{\circ} \mathrm{C}, 1200^{\circ} \mathrm{C}$, and $1300^{\circ} \mathrm{C}$ also show irregular grains (see Figures 2(b)-2(d)) and the degree of coalescence among grains increased as the temperature increases. A zoom of the samples annealed at $1150^{\circ} \mathrm{C}$ and $1300^{\circ} \mathrm{C}$ samples is shown in Figures 2(e) and 2(f), respectively. The sample annealed at $1150^{\circ} \mathrm{C}$ (see Figure 2(e)) shows a morphology composed of bars (0.3-0.8 $\mu \mathrm{m}$ of average length), hexagons $(0.2-0.5 \mu \mathrm{m}$ of average diameter), and irregular grains $(0.1-0.5 \mu \mathrm{m}$ of average size) and those ones are coalesced together to form bigger micrograins. In addition, the sample annealed at $1300^{\circ} \mathrm{C}$ consisted only in overlapped microhexagons with sizes in the range of $0.1-1.4 \mu \mathrm{m}$. Table 1 summarizes the morphologies found for each sample in this work.

3.2. Optical Properties. Figure 3 shows the diffuse reflectance spectra of samples with different annealing temperatures from $1000^{\circ} \mathrm{C}$ to $1300^{\circ} \mathrm{C}$. The spectra show that the samples are highly reflective for wavelengths above $456 \mathrm{~nm}$ and they have a huge absorption band in the range of $225 \mathrm{~nm}-456 \mathrm{~nm}$. The sample annealed at $1000^{\circ} \mathrm{C}$ showed the highest absorption of light in the visible range. The reflectance spectra show two main absorption bands: the first one is centered at $270 \mathrm{~nm}$ and it is attributed to the absorption of $\mathrm{Eu}^{2+}$ ions $[8,9]$; the second absorption band located at $385 \mathrm{~nm}$ is attributed to $5 \mathrm{~d} \rightarrow 4 \mathrm{f}$ allowed transition of $\mathrm{Eu}^{2+}$ [14]. The band-gap values of the samples were estimated by using the Kubelka-Munk function methodology $[15,16]$. Figure 4 shows the KubelkaMunk function for each sample; the values of band gap were obtained by intercepting the extrapolated linear part of the curves with the $x$-axis of the plot $(\mathrm{K}-\mathrm{M})^{1 / 2}$ versus energy $(\mathrm{eV})$. After this, the values of band-gaps obtained were in the range of 5.5-5.8 eV. Those high values suggest that our material behaves as an insulator.

Figure 5(a) depicts the excitation spectra of the samples annealed at different temperatures that were obtained by monitoring the emission at $455 \mathrm{~nm}$. Those excitation spectra are broad bands centered at $363 \mathrm{~nm}$ and they are composed of three peaks at $270 \mathrm{~nm}, 355 \mathrm{~nm}$, and $372 \mathrm{~nm}$. The excitation peaks at $372 \mathrm{~nm}$ and $355 \mathrm{~nm}$ are related to $\mathrm{Eu}^{2+}$ excitation [9, 17] while the shoulder observed at $270 \mathrm{~nm}$ is associated with the well-known Eu-O charge transfer band [18]. Figure 5(b) shows the emission spectra of the samples annealed in the range of $1000^{\circ} \mathrm{C}-1300^{\circ} \mathrm{C}$; it shows for all the samples an asymmetrical emission band centered at $\lambda_{\mathrm{em}}=455 \mathrm{~nm}$ which is attributed to the $4 \mathrm{f}^{6} 5 \mathrm{~d}^{1} \rightarrow 4 \mathrm{f}^{6}\left({ }^{8} \mathrm{~S}_{7 / 2}\right)$ allowed transitions of the $\mathrm{Eu}^{2+}[3,9,19,20]$. This figure also shows on the left side images of the samples under UV and we can appreciate how the phosphorescent intensity increases as the temperature increases; however, the intensity decreased after we annealed the samples at $1300^{\circ} \mathrm{C}$. This decrease of luminescence as a function of the temperature increase has been observed in $\mathrm{SrAl}_{2} \mathrm{O}_{4}: \mathrm{Eu}^{2+}, \mathrm{Dy}^{3+}$ and it is attributed to higher degree of coalescence of particles, which, in turn, decreases the surface where the photoluminescence process can occur [21]. The asymmetrical band profiles shown in Figure 5(b) are related to the simultaneous presence of the 


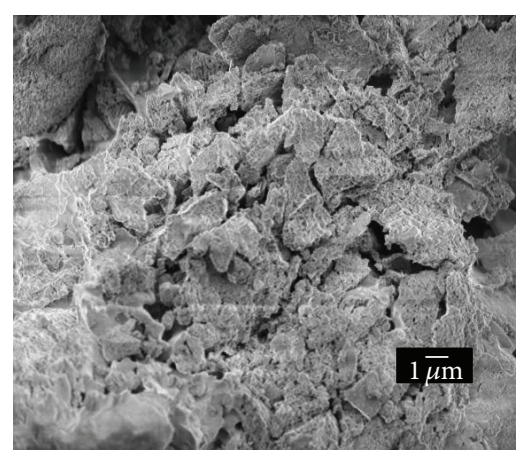

(a)

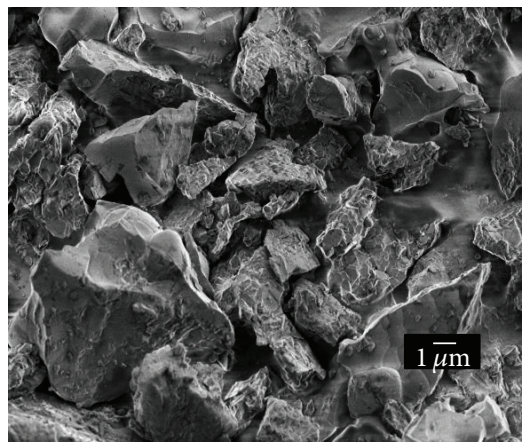

(d)

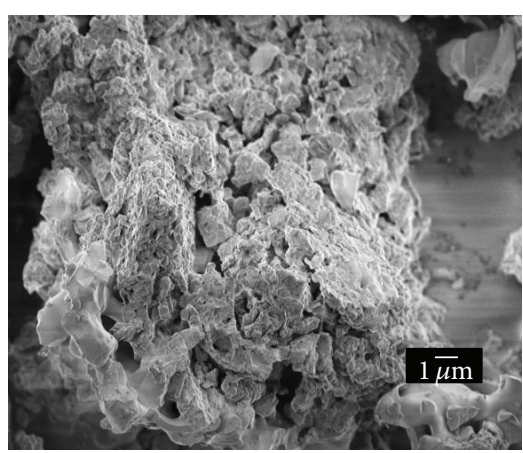

(b)

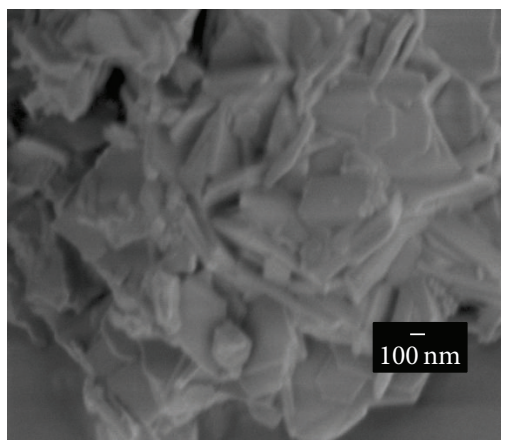

(e)

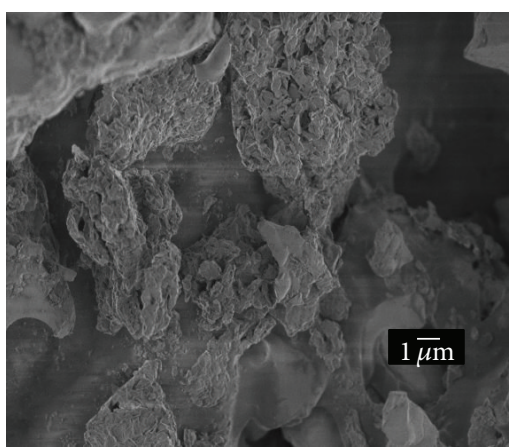

(c)

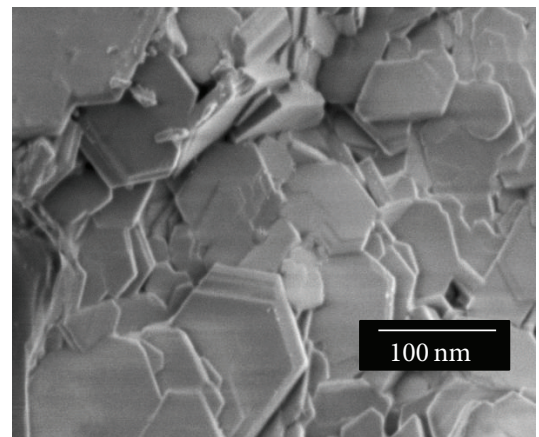

(f)

Figure 2: SEM images of samples annealed at (a) $1000^{\circ} \mathrm{C}$, (b) $1150^{\circ} \mathrm{C}$, (c) $1200^{\circ} \mathrm{C}$, and (d) $1300^{\circ} \mathrm{C}$. (e) and (f) are a zoom of the samples annealed at $1150^{\circ} \mathrm{C}$ and $1300^{\circ} \mathrm{C}$, respectively.

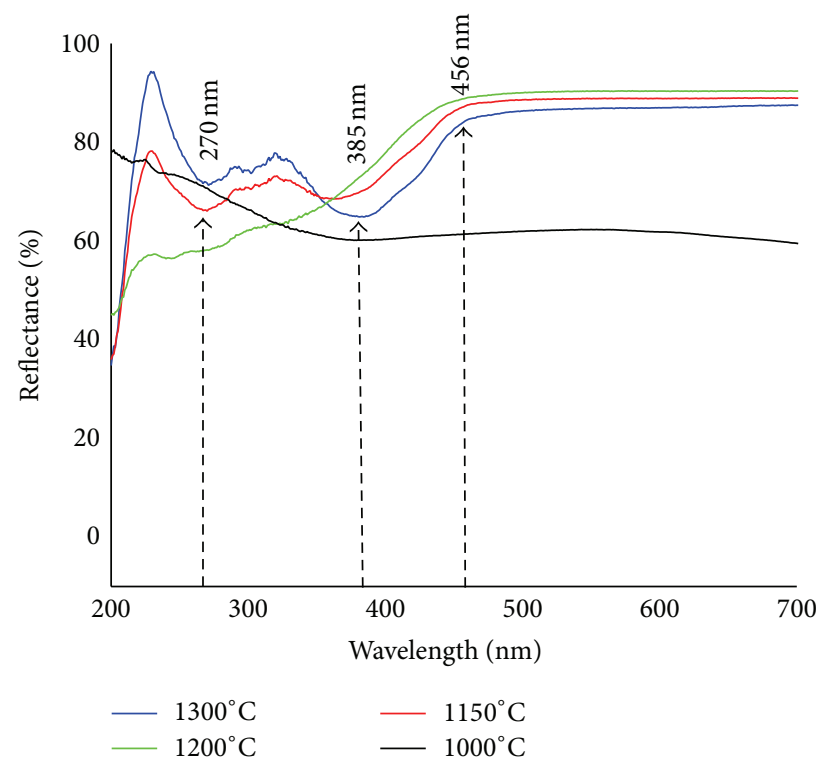

FIGURE 3: Reflectance diffuse spectra of the samples annealed at different temperatures.

$\mathrm{SrAl}_{2} \mathrm{O}_{4}$ and $\mathrm{Sr}_{3} \mathrm{Al}_{32} \mathrm{O}_{51}$ phases as observed in the XRD patterns. In both phases, the $\mathrm{Eu}^{2+}$ ions should be substituting the $\mathrm{Sr}^{2+}$ ions and, therefore, we observed a combined emission of $\mathrm{SrAl}_{2} \mathrm{O}_{4}: \mathrm{Eu}^{2+} / \mathrm{Sr}_{3} \mathrm{Al}_{32} \mathrm{O}_{51}: \mathrm{Eu}^{2+}$ which produced a broad blue-green emission band centered at $455 \mathrm{~nm}$. If we have only

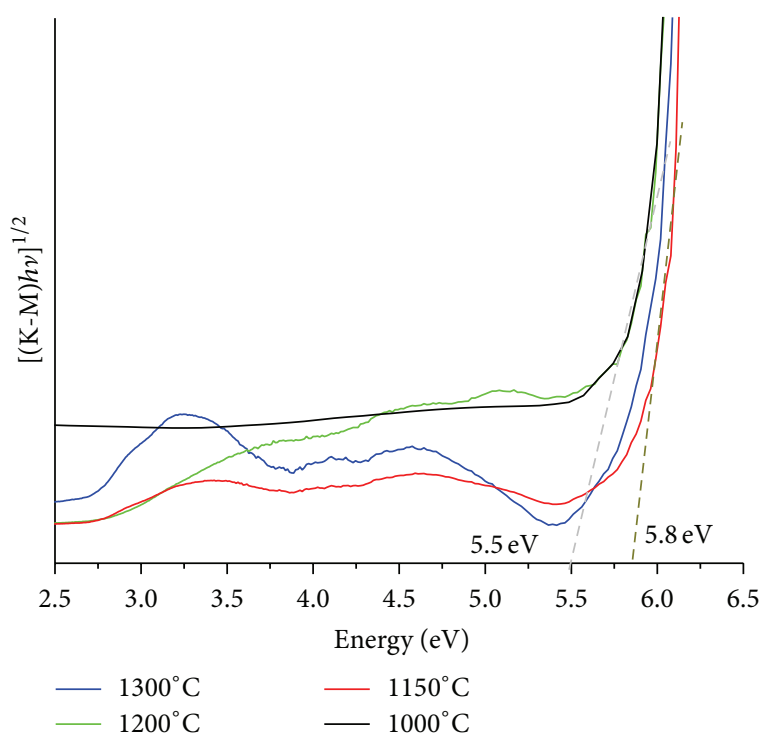

Figure 4: Plot of the Kubelka-Munk functions versus energy in eV for all samples annealed at different temperatures. The dashed lines are the tangent lines related to the procedure for the estimation of the band-gap energy; the intersection of the dashed lines with the horizontal axis gave us the values of the band-gap energy.

$\mathrm{SrAl}_{2} \mathrm{O}_{4}: \mathrm{Eu}^{2+}$ or $\mathrm{Sr}_{3} \mathrm{Al}_{32} \mathrm{O}_{51}: \mathrm{Eu}^{2+}$, we should observe a sharp emission band of $\mathrm{Eu}^{2+}$ centered at $516 \mathrm{~nm}\left(\mathrm{SrAl}_{2} \mathrm{O}_{4}: \mathrm{Eu}^{2+}\right)$ or at $450 \mathrm{~nm}\left(\mathrm{Sr}_{3} \mathrm{Al}_{32} \mathrm{O}_{51}: \mathrm{Eu}^{2+}\right)[3,19,20]$ but those single 


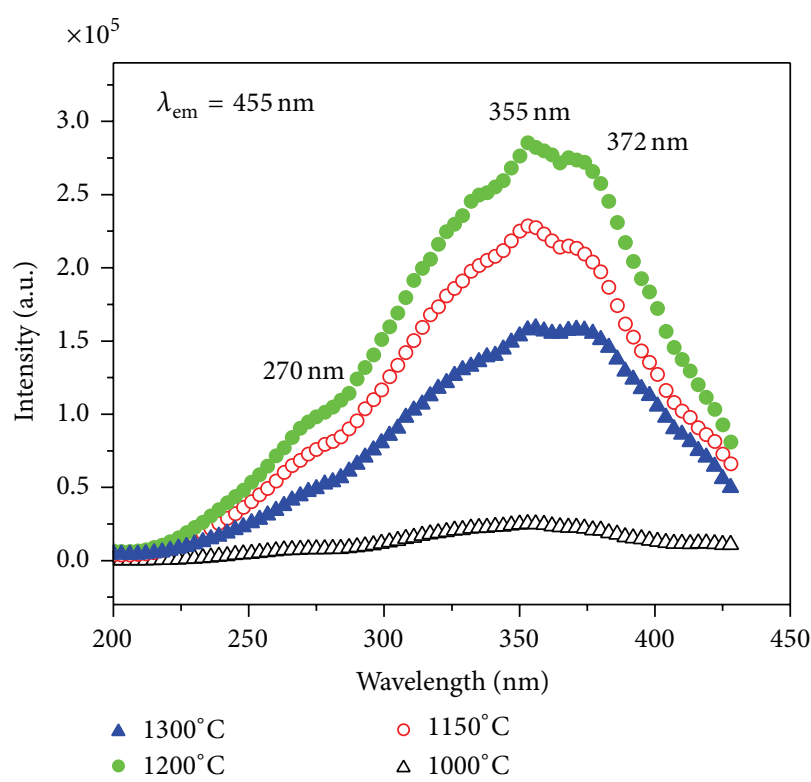

(a)

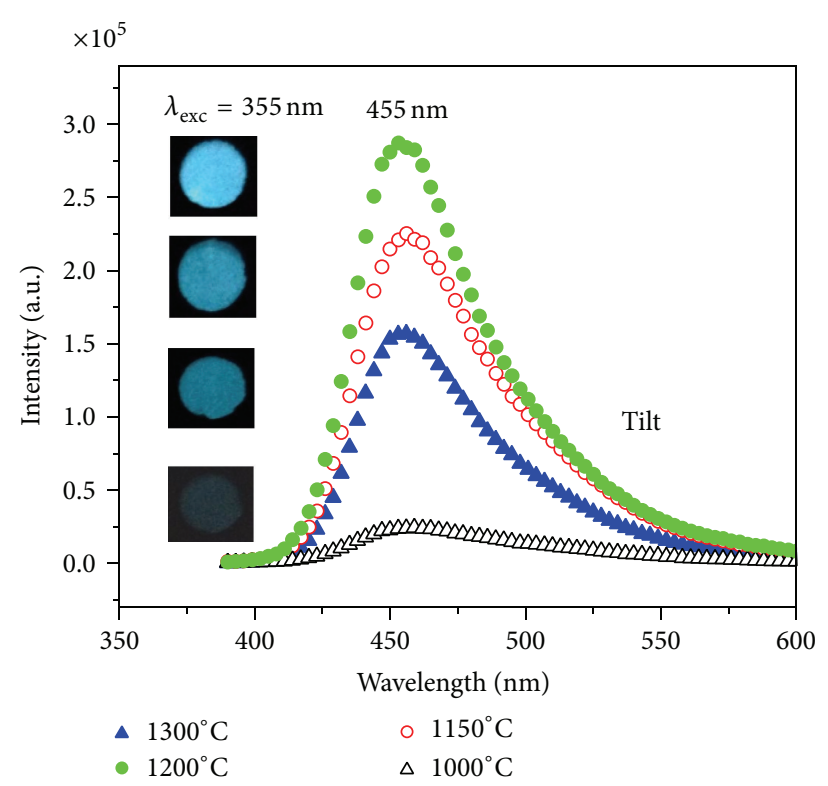

(b)

Figure 5: (a) Excitation spectra $\left(\lambda_{\mathrm{em}}=455 \mathrm{~nm}\right)$ and (b) emission spectra $\left(\lambda_{\text {exc }}=355 \mathrm{~nm}\right)$ of the samples annealed at different temperatures.

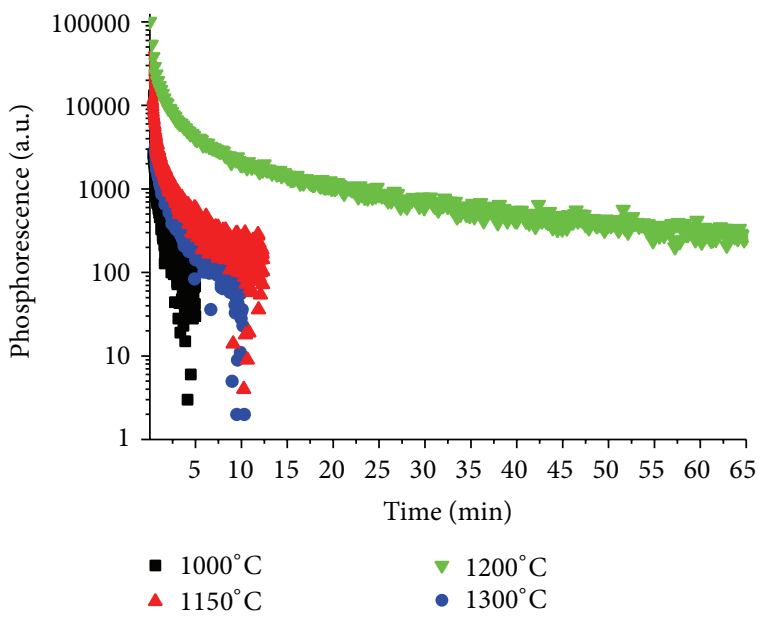

FIGURE 6: Decay time curves of aluminate/aluminosilicate powders after excitation with UV light at $365 \mathrm{~nm}$.

emissions were not observed in our case. Moreover, the $\mathrm{NaSiAlO}_{4}$ phase does not contribute to the overall emission since it did not show yellow-orange emissions in the visible region under UV irradiation [22]. Further, it is worth noting that no emission of $\mathrm{Eu}^{3+}$ was observed, which suggests that our process of reduction is good enough to dope with only $\mathrm{Eu}^{2+}$.

Figure 6 shows the phosphorescence decay curves of the samples annealed at different temperatures. Those ones were measured immediately after we stopped the excitation with UV light at $365 \mathrm{~nm}$ (we were exciting the samples during 5 minutes). As expected, the phosphorescence intensity of the sample annealed at $1200^{\circ} \mathrm{C}$ was the highest and it decreased by three orders of magnitude after 65 minutes, while the rest of samples decreased their intensity by three orders of magnitude after only 10 minutes. This trend can be related to the fact that we have bars and hexagons at the same time in the sample annealed at $1200^{\circ} \mathrm{C}$, since the other samples had grains or only hexagons and their intensity was lower. This means that bars can favor the phosphorescence but irregular grains can be detrimental for it. Furthermore, the mixture of morphologies can create intrinsic defects which enhances the phosphorescence intensity as reported in literature [23, 24]. We measured the luminance and CIE coordinates of our samples and the results are presented in Table 1; the sample annealed at $1200^{\circ} \mathrm{C}$ had the highest luminance $\left(40 \mathrm{Cd} / \mathrm{m}^{2}\right)$ and its CIE coordinates were $(0.1589,0.1972)$; this last coordinate indicates that the color of phosphorescence is located in the blue-green region. Finally, the CIE coordinates of the rest of samples were similar even though the annealing temperature increased from $1000^{\circ} \mathrm{C}$ to $1300^{\circ} \mathrm{C}$ (see Table 1 ).

3.3. Photocatalytic Activity of Powders. Photocatalysis experiments were achieved by monitoring the percentage degradation of methylene blue $(\mathrm{MB})$ in aqueous solution. Typically, the $\mathrm{MB}$ shows an absorbance band $(A)$ at $665 \mathrm{~nm}$ and we measured the absorbance intensity of this peak as a function of time, since a decrease of intensity of this band indicates a decrement of the $\mathrm{MB}$ concentration $(C)$. The following equation was used in order to calculate the $\mathrm{MB}$ degradation (\%) as function of the time $[25,26]$ :

$$
\text { Degradation (\%) }=\frac{A_{0}-A_{t}}{A_{0}} \times 100 \text {, }
$$

where $A_{0}$ and $A_{t}$ are the absorbance intensity values of the dye solution before and after irradiation, respectively. Figure 7 (a) shows the percentage degradation of $\mathrm{MB}$ as a function of time. The degradation percentages of $\mathrm{MB}$ for 


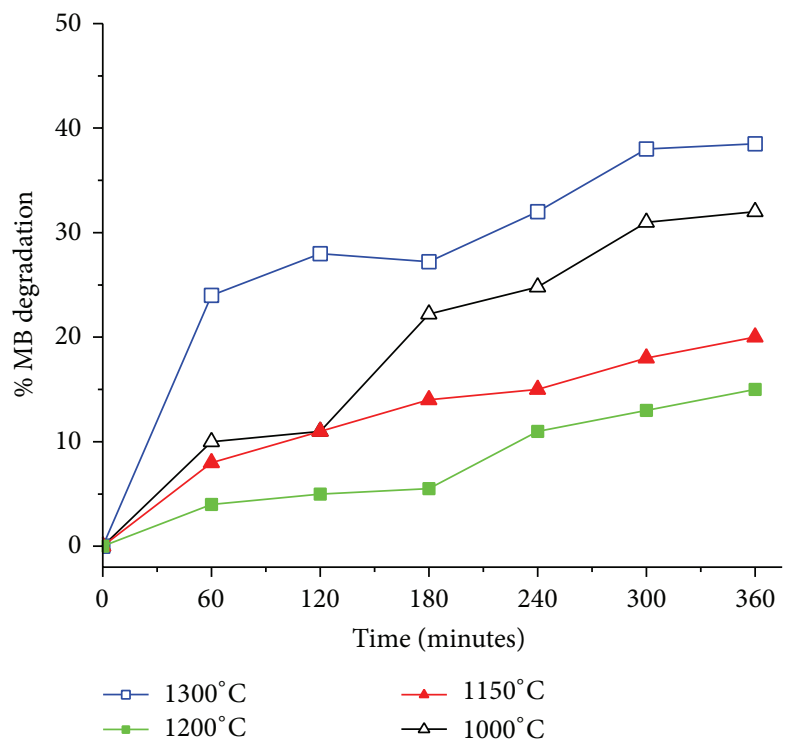

(a)

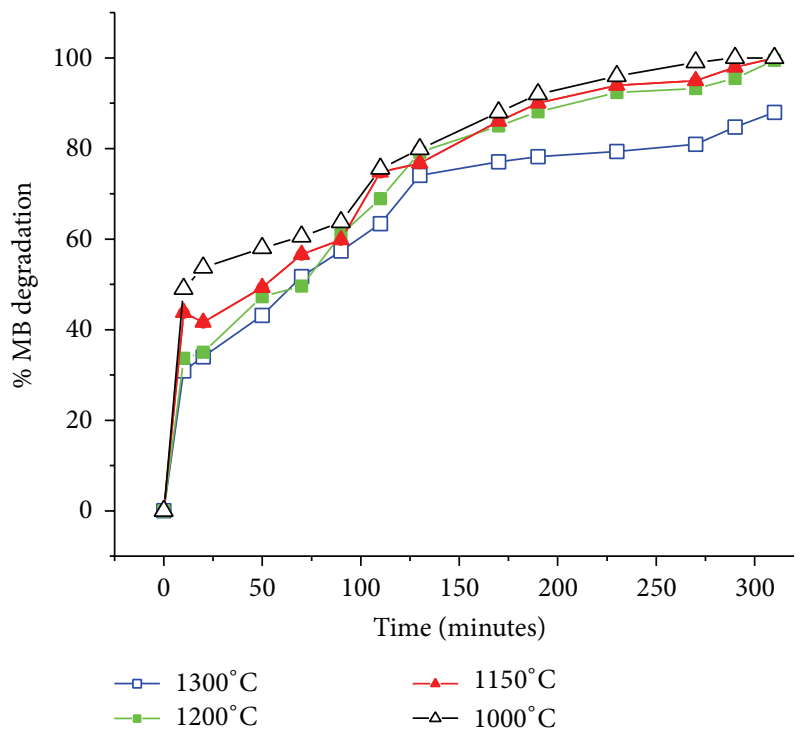

(b)

FIgURE 7: Degradation curves of MB: (a) under UV light at $365 \mathrm{~nm}$ and (b) under solar irradiation.

the samples annealed at $1000^{\circ} \mathrm{C}, 1150^{\circ} \mathrm{C}, 1200^{\circ} \mathrm{C}$, and $1300^{\circ} \mathrm{C}$ after $360 \mathrm{~min}$ of UV excitation were $32 \%, 20 \%, 15 \%$, and $38.5 \%$, respectively. Thus, the samples annealed at $1000^{\circ} \mathrm{C}$ and $1300^{\circ} \mathrm{C}$ presented the highest percentage degradation and the lowest luminescent intensities. In contrast, the samples with the highest luminescent intensity $\left(1150^{\circ} \mathrm{C}\right.$ and $\left.1200^{\circ} \mathrm{C}\right)$ exhibited the lowest photocatalytic activity. The decrease in the photocatalytic activity has been observed in other luminescent systems $[25,27]$ and this is due to the fact that the samples with lower luminescence generate more free-carriers (electron or holes) during the phosphorescence process compared with the samples with higher luminescence which use most of the electron/hole pairs to generate light emission. In consequence, as the availability of free-carriers is better, the photocatalytic activity is enhanced [28, 29]. Figure 7(b) shows the percentage degradation of the samples exposed to solar irradiation as a function of time. It is observed that the samples annealed at $1000^{\circ} \mathrm{C}, 1150^{\circ} \mathrm{C}$, and $1200^{\circ} \mathrm{C}$ degraded $100 \%$ the $\mathrm{MB}$ dye after $300 \mathrm{~min}$; this means an increase of $68 \%, 80 \%$, and $85 \%$ of the MB degradation compared with the results obtained under UV light. The sample calcined at $1300^{\circ} \mathrm{C}$ degrades only $~ 88 \%$ of methylene blue in water solution after $360 \mathrm{~min}$ (see Figure 7(b)). This lower degradation percentage is related to the fact that higher annealing temperature promotes the coalescence of grains, which, in turn, reduces the surface area and this reduces the amount of methylene blue molecules adsorbed on the powders. This can be corroborated from SEM images, since we find bigger pieces of coalesced material in the samples annealed at $1300^{\circ} \mathrm{C}$ in comparison with the rest of samples (see Figures 2(a)-2(d)).

Based on the results mentioned above, we consider that our phosphors have modest photocatalysis activity (under UV light) compared to conventional $\mathrm{TiO}_{2}$ nanoparticles [26,
28]. However, an advantage of our (Eu,Dy)-doped strontium aluminates/aluminosilicates as photocatalyst is the fact that they can be separated easily from water by using simple precipitation, which is more difficult for conventional $\mathrm{TiO}_{2}$ nanoparticles. The best performance of our phosphors is presented under solar irradiation; this suggests that they can be used as photocatalysts in water treatment plans. We are currently working to obtain only one single phase, that is, only strontium aluminate or aluminosilicates in order to obtain the photocatalytic performance of each phase separately. Those results will be published in a subsequent article.

\section{Conclusions}

Strontium aluminate/aluminosilicate phosphorescent phosphors based on the mixture of $\mathrm{SrAl}_{2} \mathrm{O}_{4}: \mathrm{Eu}^{2+}, \mathrm{Dy}^{3+}$, $\mathrm{Sr}_{3} \mathrm{Al}_{32} \mathrm{O}_{51}: \mathrm{Eu}^{2+}, \mathrm{Dy}^{3+}$, and $\mathrm{NaSiAlO}_{4}$ were successfully fabricated by combustion synthesis and postannealed. The blue-green phosphorescence emission at $455 \mathrm{~nm}$ is ascribed to the $4 \mathrm{f}-5 \mathrm{~d}$ allowed transition of the $\mathrm{Eu}^{2+}$. The sample with the longest phosphorescence was that annealed at $1200^{\circ} \mathrm{C}$ and it had a luminance of $40 \mathrm{Cd} / \mathrm{m}^{2}$. The photocatalyst experiments with our samples demonstrated that these samples annealed at $1000^{\circ} \mathrm{C}$ and $1300^{\circ} \mathrm{C}$ showed the lowest luminescence intensity but the highest percentage degradation of MB under UV excitation at $365 \mathrm{~nm}(32 \%$ and $38.5 \%$, resp.). When solar irradiation was used for the photocatalysis experiments, total degradation of $\mathrm{MB}$ was observed by using the samples annealed at $1000^{\circ} \mathrm{C}, 1150^{\circ} \mathrm{C}$, and $1200^{\circ} \mathrm{C}$ after 300 minutes. Also those powders were separated easily from water by simple precipitation. Hence, the results suggest that our strontium aluminate/aluminosilicate phosphorescent blue phosphor powders can be useful for water cleaning systems. 


\section{Competing Interests}

The authors declare that they have no competing interests.

\section{Acknowledgments}

The authors appreciate the excellent technical work performed by R. Valdivia, C. Albor, and M. Olmos. C. R. García thanks CONACYT-México for national postdoctoral fellowship, PRODEP-SEP 2015 project, and FONCYT-COECYT 2016 project. One of the author thanks Drs. R. Narro, C. Méndez, and K. Linganna for their helpful comments and discussions.

\section{References}

[1] K. van den Eeckhout, D. Poelman, and P. F. Smet, "Persistent luminescence in non-Eu ${ }^{2+}$-doped compounds: a review," Materials, vol. 6, no. 7, pp. 2789-2818, 2013.

[2] T. Matsuzawa, Y. Aoki, N. Takeuchi, and Y. Murayama, "A new long phosphorescent phosphor with high brightness, $\mathrm{SrAl}_{2} \mathrm{O}_{4}: \mathrm{Eu}^{2+}, \mathrm{Dy}^{3+}$," Journal of the Electrochemical Society, vol. 143, no. 8, pp. 2670-2673, 1996.

[3] N. M. Son, L. T. T. Vien, L. V. K. Bao, and N. N. Trac, "Synthesis of $\mathrm{SrAl}_{2} \mathrm{O}_{4}: \mathrm{Eu}^{2+} \mathrm{Dy}^{3+}$ phosphorescence nanosized powder by combustion method and its optical properties," Journal of Physics: Conference Series, vol. 187, article 012017, 2009.

[4] K. Van den Eeckhout, P. F. Smet, and D. Poelman, "Persistent luminescence in $\mathrm{Eu}^{2+}$-doped compounds: a review," Materials, vol. 3, no. 4, pp. 2536-2566, 2010.

[5] J. B. Zhong, D. Ma, X. Y. He, J. Z. Li, and Y. Q. Chen, "Sol-gel preparation and photocatalytic performance of $\mathrm{TiO}_{2} / \mathrm{SrAl}_{2} \mathrm{O}_{4}$ : $\mathrm{Eu}^{2+}, \mathrm{Dy}^{3+}$ toward the oxidation of gaseous benzene," Journal of Sol-Gel Science and Technology, vol. 52, no. 1, pp. 140-145, 2009.

[6] H. Li, S. Yin, Y. Wang, and T. Sato, "Persistent luminescence assisted photocatalytic properties of $\mathrm{CaAl}_{2} \mathrm{O}_{4}:(\mathrm{Eu}, \mathrm{Nd}) /$ $\mathrm{TiO}_{2-x} \mathrm{~N}_{y}$ and $\mathrm{Sr}_{4} \mathrm{Al}_{14} \mathrm{O}_{25}:(\mathrm{Eu}, \mathrm{Dy}) / \mathrm{TiO}_{2-x} \mathrm{~N}_{y}$, Journal of $\mathrm{Mo}$ lecular Catalysis A: Chemical, vol. 363-364, pp. 129-133, 2012.

[7] H. Li, S. Yin, Y. Wang, T. Sekino, S. W. Lee, and T. Sato, "Green phosphorescence-assisted degradation of rhodamine $\mathrm{B}$ dyes by $\mathrm{Ag}_{3} \mathrm{PO}_{4}$," Journal of Materials Chemistry A, vol. 1, no. 4, pp. 1123 1126, 2013.

[8] T. Peng, L. Huajun, H. Yang, and C. Yan, "Synthesis of $\mathrm{SrAl}_{2} \mathrm{O}_{4}: \mathrm{Eu}$, Dy phosphor nanometer powders by sol-gel processes and its optical properties," Materials Chemistry and Physics, vol. 85, no. 1, pp. 68-72, 2004.

[9] F. Clabau, X. Rocquefelte, S. Jobic et al., "Mechanism of phosphorescence appropriate for the long-lasting phosphors $\mathrm{Eu}^{2+}$-doped $\mathrm{SrAl}_{2} \mathrm{O}_{4}$ with codopants $\mathrm{Dy}^{3+}$ and $\mathrm{B}^{3+}$, "Chemistry of Materials, vol. 17, no. 15, pp. 3904-3912, 2005.

[10] A. L. Linsebigler, G. Lu, and J. T. Yates Jr., "Photocatalysis on $\mathrm{TiO}_{2}$ surfaces: principles, mechanisms, and selected results," Chemical Reviews, vol. 95, no. 3, pp. 735-758, 1995.

[11] G. Federici, B. J. Shaw, and R. D. Handy, "Toxicity of titanium dioxide nanoparticles to rainbow trout (Oncorhynchus mykiss): gill injury, oxidative stress, and other physiological effects," Aquatic Toxicology, vol. 84, no. 4, pp. 415-430, 2007.

[12] X. Zhu, Y. Chang, and Y. Chen, "Toxicity and bioaccumulation of $\mathrm{TiO}_{2}$ nanoparticle aggregates in Daphnia magna," Chemosphere, vol. 78, no. 3, pp. 209-215, 2010.
[13] W.-W. Yang, Y. Wang, B. Huang et al., " $\mathrm{TiO}_{2}$ nanoparticles act as a carrier of Cd bioaccumulation in the ciliate Tetrahymena thermophila," Environmental Science \& Technology, vol. 48, no. 13, pp. 7568-7575, 2014.

[14] T. W. Kim and H. L. Park, "Observation of two valence states of $\mathrm{Eu}$ in a $\mathrm{SrS}_{x} \mathrm{O}_{1-x}: \mathrm{Eu}_{y}$ phosphor," Solid State Communications, vol. 85, no. 7, pp. 635-637, 1993.

[15] J. Tauc, "Optical properties and electronic structure of amorphous Ge and Si," Materials Research Bulletin, vol. 3, no. 1, pp. 37-46, 1968.

[16] A. Escobedo Morales, E. Sanchez Mora, and U. Pal, "Use of diffuse reflectance spectroscopy for optical characterization of un-supported nanostructures," Revista Mexicana de Física, vol. 53, pp. 18-22, 2007.

[17] X. Luo, W. Cao, and F. Sun, “The development of silicate matrix phosphors with broad excitation band for phosphor-convered white LED," Chinese Science Bulletin, vol. 53, no. 19, pp. $2923-$ 2930, 2008.

[18] G. Blasse and B. C. Grabmaier, Luminescent Materials, vol. 2, Springer, Berlin, Germany, 1994.

[19] Y.-F. Xu, D.-K. Ma, M.-L. Guan, X.-A. Chen, Q.-Q. Pan, and S.-M. Huang, "Controlled synthesis of single-crystal $\mathrm{SrAl}_{2} \mathrm{O}_{4}: \mathrm{Eu}^{2+}, \mathrm{Dy}^{3+}$ nanosheets with long-lasting phosphorescence," Journal of Alloys and Compounds, vol. 502, no. 1, pp. 3842, 2010.

[20] M. A. Kale, C. P. Joshi, and S. V. Moharil, "Preparation and photoluminescence study of $\mathrm{Eu}^{2+}$ doped $\mathrm{SrAl}_{4} \mathrm{O}_{7}$ and $\mathrm{Sr}_{3} \mathrm{Al}_{32} \mathrm{O}_{51}$," International Journal of Chemical and Physical Sciences, vol. 1 , no. 2, pp. 35-39, 2012.

[21] M. Gaft, W. Strek, L. Nagli, G. Panczer, G. R. Rossman, and L. Marciniak, "Laser-induced time-resolved luminescence of natural sillimanite $\mathrm{Al}_{2} \mathrm{SiO}_{5}$ and synthetic $\mathrm{Al}_{2} \mathrm{SiO}_{5}$ activated by chromium," Journal of Luminescence, vol. 132, no. 11, pp. 28552862, 2012.

[22] S. Deng, Z. Xue, Q. Yang et al., "Surface modification of $\mathrm{MAl}_{2} \mathrm{O}_{4}: \mathrm{Eu}^{2+}, \mathrm{Dy}^{3+}(\mathrm{M}=\mathrm{Sr}, \mathrm{Ca}, \mathrm{Ba})$ phosphors to enhance water resistance by combustion method," Applied Surface Science, vol. 282, pp. 315-319, 2013.

[23] T. Laamanen, Defects in persistent luminescence materials [Ph.D. thesis], Universidad of Turku, Graduate School of Materials Research, Turku, Finland, 2011, S. Ser and A. I. Osa.

[24] H. Ryu and K. S. Bartwal, "Defect structure and its relevance to photoluminescence in $\mathrm{SrAl}_{2} \mathrm{O}_{4}: \mathrm{Eu}^{2+}, \mathrm{Nd}^{3+}$, Physica B: Condensed Matter, vol. 404, no. 12-13, pp. 1714-1718, 2009.

[25] R. Borja-Urby, L. A. Díaz-Torres, P. Salas, E. Moctezuma, M. Vega, and C. Ángeles-Chávez, "Structural study, photoluminescence, and photocatalytic activity of semiconducting $\mathrm{BaZrO}_{3}: \mathrm{Bi}$ nanocrystals," Materials Science and Engineering: $B$, vol. 176, no. 17, pp. 1382-1387, 2011.

[26] A. Houas, H. Lachheb, M. Ksibi, E. Elaloui, C. Guillard, and J.-M. Herrmann, "Photocatalytic degradation pathway of methylene blue in water," Applied Catalysis B: Environmental, vol. 31, no. 2, pp. 145-157, 2001.

[27] D. Wojcieszak, D. Kaczmarek, J. Domaradzki, and M. Mazur, "Correlation of photocatalysis and photoluminescence effect in relation to the surface properties of $\mathrm{TiO}_{2}: \mathrm{Tb}$ thin films," International Journal of Photoenergy, vol. 2013, Article ID 526140, 9 pages, 2013.

[28] S.-Y. Kim, T.-H. Lim, T.-S. Chang, and C.-H. Shin, "Photocatalysis of methylene blue on titanium dioxide nanoparticles synthesized by modified sol-hydrothermal process of $\mathrm{TiCl}_{4}$," Catalysis Letters, vol. 117, no. 3-4, pp. 112-118, 2007. 
[29] C. R. García, L. A. Diaz-Torres, P. Salas, M. Guzman, and C. Angeles-Chavez, "Photoluminescent and photocatalytic properties of bismuth doped strontium aluminates blended with titanium dioxide," Materials Science in Semiconductor Processing, vol. 37, pp. 105-111, 2015. 

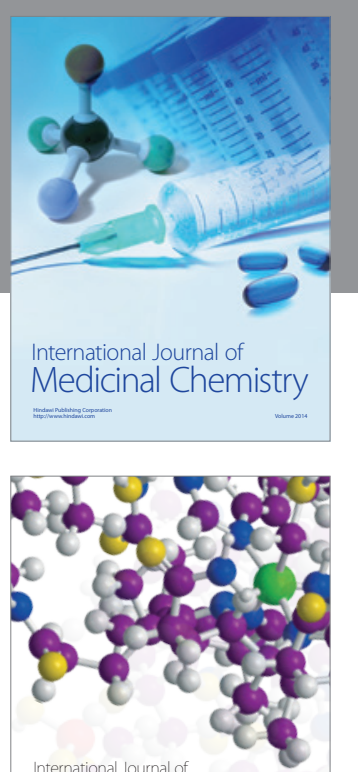

Carbohydrate Chemistry

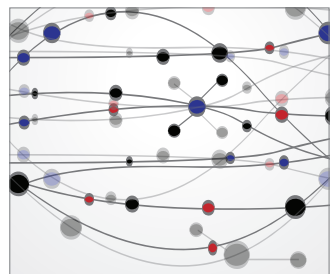

The Scientific World Journal
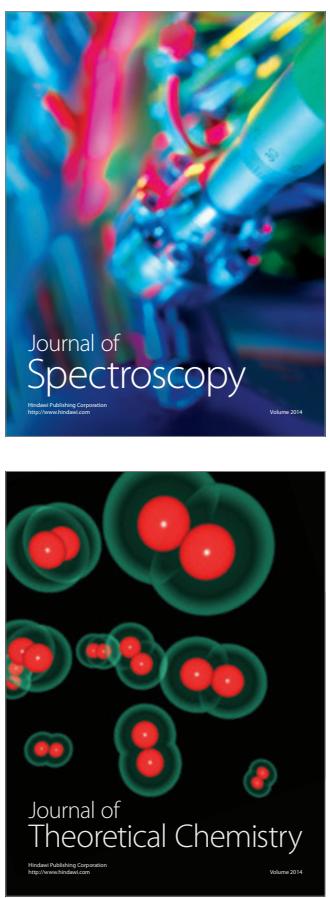
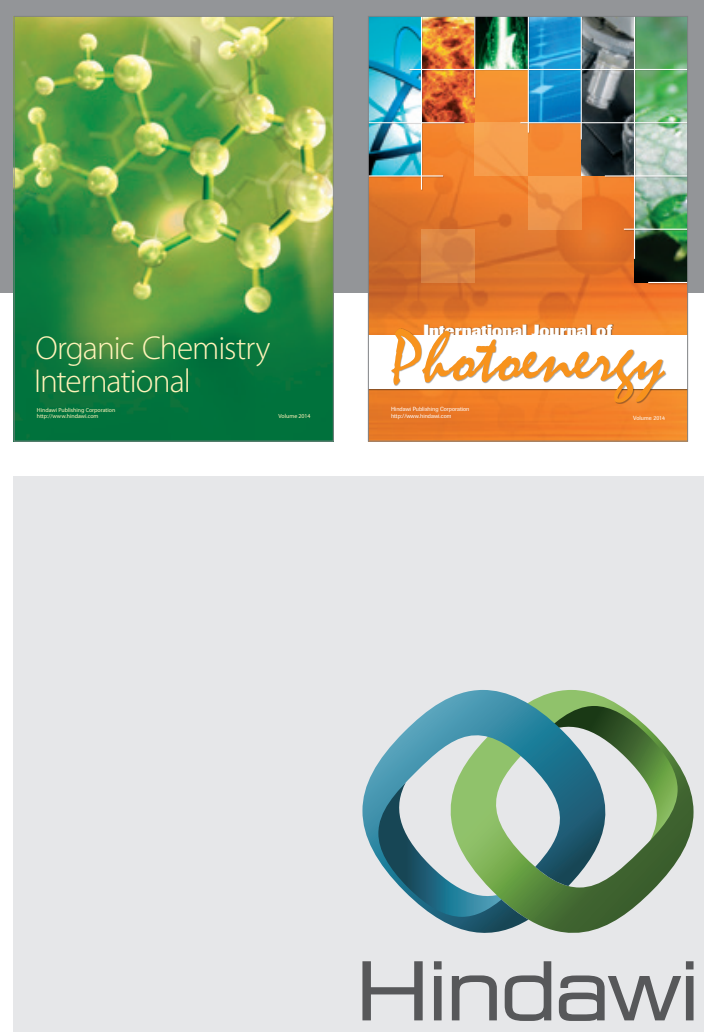

Submit your manuscripts at

http://www.hindawi.com

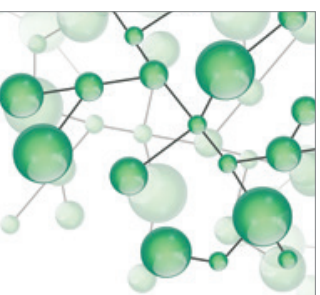

International Journal of

Inorganic Chemistry

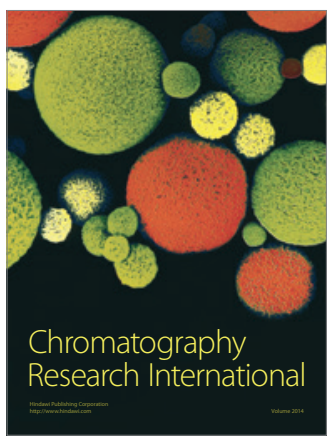

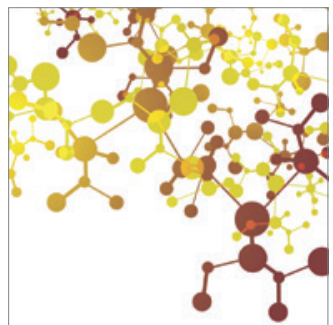

Applied Chemistry
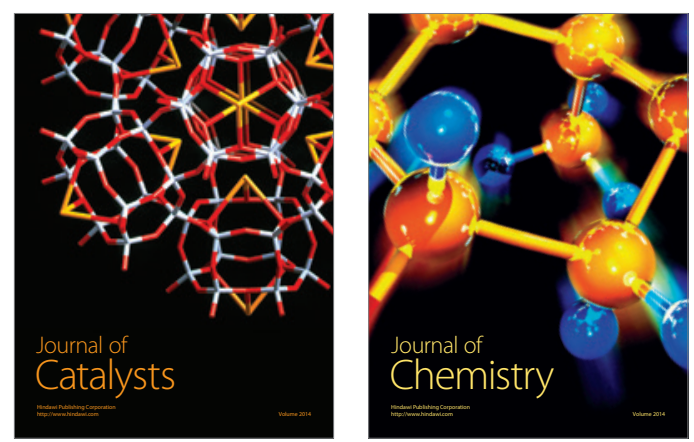
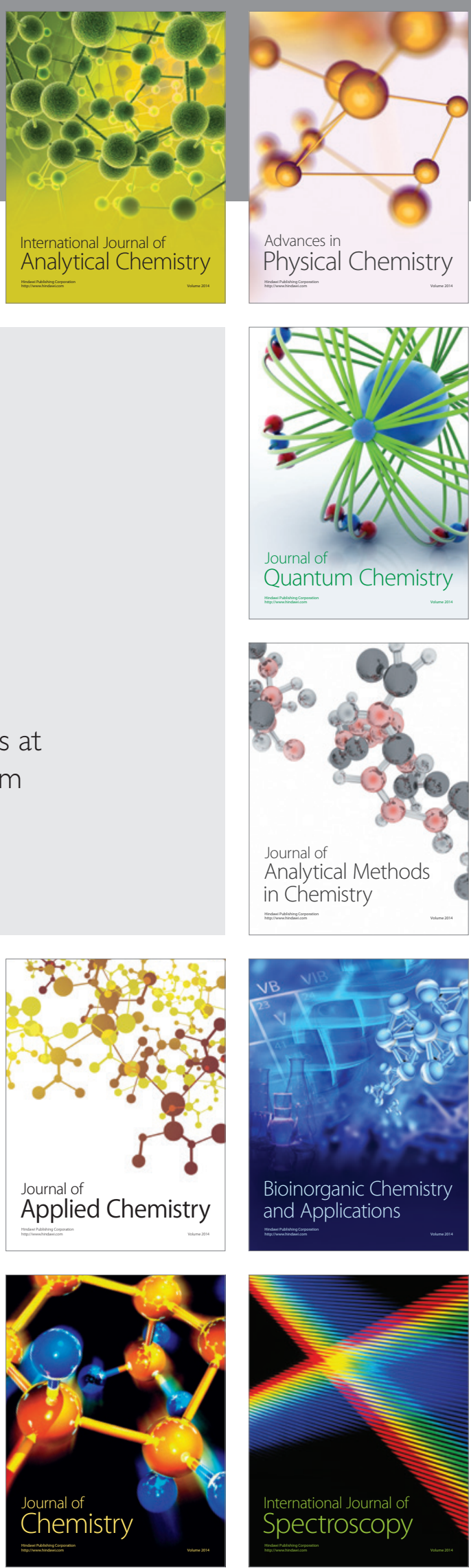